\section{Comparação experimental entre enxertos autógenos de córnea e conjuntiva no reparo de ceratectomias superficiais em cães (Canis familiares, Linnaeus, 1758). Estudo clínico e morfológico}

\author{
Experimental comparison between corneal and conjunctival au- \\ togenous grafts in the repair of superficial keratectomies in dogs \\ (Canis familiaris, Linnacus, 1758). Clinical and morfological \\ study.
}

Mirian Siliane Batista de SOUZA', José I uiz I AUS², Adriana MORAIJAS', Florêncio FICILIRFI)( ${ }^{4}$. Jaime dos Santos MAIA ${ }^{\varsigma}$, Victório VAI.ERI"
CORRESPONDENCE TO: Mirian Siliane Batista de Souza Departamento de Clinicas Veterinárias - Centro de Ciências Agrárias - Universidade Estadual de Londrina - UEL Campus Universitário - Caixa Postal 6001

86051-970-Londrina - PR - Brasi o-mail: siliane@npd.uel.br

1. Universidade Estadual de Londrina - UEL

2. Faculdade de Ciências Agrárias e Veferinárias da UNESP, Jaboticabal, SP 3. Faculdade de Medicina Veterinária e Zootecnia da USP. SP 4. Faculdade de Medicina da USP. Riberiäo Preto, SP

5. Faculdade de Ciências Agrárias e Veterinárias da UNESP, Jaboticabal, SP 6. Instituto de Patologia e Citologia "Prof. Dr. Victorio Valeri" Ltda

\title{
RESUMO
}

Foram estudadas ceratoplastias lamelares por enxertos autógenos frescos de córnea e de conjuntiva. Utilizaram-se 31 animais da espécie canina, adultos, machos ou fēmeas, clinicamente sadios. Realizaram-se ceratectomias superficiais com trépano de $5 \mathrm{~mm}$ de diâmetro na consecução de botões lamelares que incluiram epitélio e metade da espessura do estroma. Obtiveramse os tecidos para as enxertias, a partir da córnea e da conjuntiva bulbar contralateral, que foram fixados à córnea trepanada com fio de seda oftálmica número 8-0, em pontos simples separados. A evolução dos enxertos foi avaliada aos 1, 2, 7, 15, 30 e 60 dias após a cirurgia. Os resultados mostraram edema, vasos neoformados, congestāo, hemorragia, infiltrado de células polimorfo e mononucleares, que tenderam a ser tornar exíguos no decurso do tempo, e fibrose tardia. Aos 60 dias, as áreas de enxertia começaram a exibir transparência em pontos distintos. Não houve diferenças entre as técnicas estudadas. A microscopia eletrônica de varredura mostrou epitelização na zona dos enxertos, já aos dois dias da implantação. Aos 15 dias, notaram-se células pavimentosas nas regiões enxertadas. Aos 30 dias, as áreas mostraram-se morfologicamente similares às da córnea normal. Neste periodo, foram também encontrados granulomas de ponto. Aos 30 dias, puderam-se visualizar projeções citoplasmáticas semelhantes às da superficie da córnea normal. Com base nos achados clínicos e morfológicos, pode-se inferir que os procedimentos investigados mostraram-se similares.

UNITERMOS: Córnea; Enxertos: Cirurgia; Transplante de córnea: Conjuntiva; Cães

\section{INTRODUÇÃO E REVISÃO DA LITERATURA}

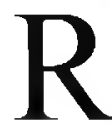
elatisamente aos processos pallológicos que afligem a cornca. destacam-se als ceratiles ulecrativas e demais centidades que determinam. A enfermidade pode evoluir para reparaçào através de mitoses e migração celular centripeta ${ }^{18 .}$ 2t. "4, ou tornar-se grave. mormente na perpetuação da causa ou na invasão por microorganismos ${ }^{2+}$

Dor. blefarospasmo, epifora. descarga ocular, folofobia. edema e vascularizaçào it ir sầo sintomas habituais. Fundamentamse as condutas terapeuticas no alivio da dor. na profilaxia de descemetoceles, de perluraçào total e de endoftalmites. condutas em ceratoplastials resersam-se aos casos graves. Neste sentido, ha que se considerar très aspectos: formal a avanço nos procedimentos de obtençán de enxertes. métodos de conservaçáo e técnicas de transplantaçiòn ${ }^{2}$. listudos neste sentido foram conduzidos por Guimarĩes" (1979) \& Panchbhai; Kulkarni²6(1986).

Polack ${ }^{3}(1962)$ descreveu rejeiçào tecidual a enxertos alogenos. Rochat ${ }^{29}(1962)$ nâo a citou. Khodadoust: Silverstein't (1969) verificaram histoincompatibilidade em 50\% de cisos experimentalmente estudados em enxertia alógena. Medeiros? (1973) comparou a antigenicidade de enxertos alógenos é autógenos e concluiu pelos valores da enxertia autógena.

Panshbhai; Kulkarni" (1987) compararam ceratoplastias penetrantes autógenas. alógenas e xenógenas em córneans de búlalos. Khodadoust ${ }^{13}(1973)$ realizou quatrocentas ceratoplas-tias em leporinos de laboratório. comparando córnea fresea e conservada. Os resultados oblidos falaram $\mathrm{cm}$ favor dos enxertos a fresco. comparaltivamente a outros tecidos. Silverstein: Khodadoust ${ }^{3}(1973)$ relataram a cornea como material ideal para a doaçào de fragmentos em coratoplastias. Brigheman e' al." ( I989) investigaram enxertos lamelares autógenos en córneas de càes. $\dot{\Lambda}$ microscopia eletronica de varredura visualizaram a endotelização completa da superficic posterior dos enxertos.

Thoft ${ }^{\text {th }}$ (1982) realizou enxertial conjuntival live em doze pacientes humanos. com bons resultados. Morales all al. ${ }^{33}$ (1993) 
compararam ceratoplastias por enxertos autógenos livres e pediculados de conjuntiva. Os estudos macro e microscópicos evidenciaram a superioridade dos enxertos pediculados.

Lalus (f al. ${ }^{19}(1993)$ investigaram ceraloplastias em càcs empregando adesivo a base de gelatima, resorcina e formaldeido (Colagele). As corncas foram estudadas por lécnicas macro e microscópicas e os resultados oblidos mostraram a ineficícia do procedimento. Brike ( 1991) aplicou bandagem de pelicula celulósica em lesoics experimentais do epitélio corncano cobservou completa epitelização da ferida. decorridas 48 horas de pós-operatório.

Koening: Kauliman ${ }^{15}$ (1983) utilizaram periósteo aulógeno a fresco. Barros e a ( $^{3}(1990)$ pericardio eqüino conservado $\mathrm{cm}$ glicerina c (jarcia ef al ${ }^{x}(1993)$, peritónio alógeno conservado em glicerina. em enxertias de córnea em càes, com bons resul-tados. Spoor ef al ${ }^{35}(1989)$ citaram reparaçòes autogenas de córnea com cartilagem auricular. periósteo, fascia lata, gordura dermal e esclerotica.

Com base nas técnicas estudadas no decurso dos dois últimos séculos. chegou-se hoje a conclusōes sobre materiais a serem implantados, cuidados pré-operatórios, mélodo de conservação e fixação e formas de terapia pós-enxertia. Não obstante, pouco se fez sm relação a investigaçòes comparativas entre os procedimentos já consagrados. () estudo retrospectivo fala em favor das assertivas e sugere conceber investigaçoes cotejativas.

Calcados nestes aspectos, mormente no tocante ao tempo cirúrgico, risco operatório. iatrogenicidade e valor terapêutico. alicerçam-se os objetivos da pesquisa, que compara enxertos autógenos de córnea e conjuntiva na ceratoplastia experimental $\mathrm{cm}$ cães. Para a obtençào de dados conclusivos ảs proposiçòes, alvitrouse protocolálas segundo avaliaçoes clinicas e morfológicas (microscopias óptica e eletronica de varredura).

\section{MATERIAL E MÉTODO}

\section{Animais}

Unilizaram-se 31 animais da especic canina. sem raça delinida. machos ou fêmeas, adultos, com peso corpóreo medio de $8 \mathrm{~kg}$. fornecidos pelo (anil de lixperimentação Animal do Hospital Velerinário da Faculdade de (Ciências Agrárias e Veterinárias de Jaboticabal - UNI:SP. Previamente a seleção c divisão em grupos, os caies foram clinicamente avaliados segundo protocolos rotineiros em semiologia clinica e oftámica. Posteriormente. foram identilicados a mantidos em canis apropriados, recebendo dieta balanceada c água ad lihirmm.

\section{Grupos experimentais}

(onstituiram-sc. para estudos aos 1,2, 7, 15, 30 e 60 dias de pós-operatório, seis grupos experimentais. Im a um, nos tempos. foram estudados enxertos autogenos frescos de cómea. comparalivamentea enxertos frescos de conjuntiva, nào pediculados. lambim autogenos.

\footnotetext{
'. Amplicitil - Rhodia

- Pentobarbilal Sigma Chemical

- Microscópio esteroscópio MC-M9idF Vasconcelos S.A.

- Seda 8-0 - Oftalmica - Cirumedica S.A.
}

\section{Procedimentos cirúrgicos}

Previamente as condulas operatorias. observaram-se os cuidados relativos a jejum hídrico e alimentar por 12 horas. medicação pré-anestésica a base de clorpromazinal , na dose de 1,0 mg kg de peso corpóreo. por via intravenosa e anestesia geral barbitúrica, com Pentobarbital sódico², a $3 \%$ em soluçào aquosa estéril. na dose média de $15.0 \mathrm{mg} / \mathrm{kg}$ de peso corpóreo, por via intravenosa.

Estando os animais sob efeito de anestesia geral. com auxílio de equipamento para estereoscopia” realizaram-se as condutas cirúggicas. Conduziram-se anti sepsia e proteção de campo operatório: efetuaram-se blefaroslase c fixaçào do globo ocular. Ato contínto. com trépano de $5 \mathrm{~mm}$ de diämetro. aplicado diretamente sobre a cónca. produziu-se botào lamelar compreendendo epitélio e metade da espessura do estroma. Procedeu-se à coleta de lamela doadora, compreendendo epitélio c aproximadamente metade da espessisura do estroma do olho contralateral, para a confecção das ceratoplastias córnca-cornca. Em procedimento análogo, relativamente à área receptora. porém com fração doadora collida a partir da conjunliva bulbar contralateral (ceratoplastia conjuntiva-cónea). iniciou-se o estudo cotcjativo.

Os procedimentos de fixação dos enxertos bašaram-se no emprego de suturas em pontos isolados simples, transfixando-se as lamelas doadoras, mas nào totalmente a córnea receptora, com seda trançadasiliconizada ${ }^{+1}$ 8-0, a uma eqüidistancia de aproximadamente $1 \mathrm{~mm}$.

Como medidas pós-operatórias, cletuaram-sc, a intervalos de 12 horas, limpeza e profilaxia com antibiótico de uso oftálmicol. Para que fatores comportamentais. relativos à automutilaçào. não interferissem com a evolução pós-operatória, empregou-se "colar clizabclano"

\section{Protocolos de avaliação \\ Avaliaçào clínica}

Avaliaram-se os fenomenos intercorrentes com a evoluçaio clinica pos-operatoria das ceratoplastias, tais como fotolobia. blefarospasmo, edema, neovascularizacio, Iransparencia. iridocicliles reflexas e tipos de secreçào, yuantificandos subjelivamente.

\section{Morfologia \\ Microscopia óptica}

Para a histologia à luz da microscopia optica. as cormeas operadas foram retiradas. submetidas a fixação $\mathrm{cm}$ formaldeido tamponado. em soluçao aquosa a $10 \%$. reduridas, incluidas em parafina. cortadas a uma espessura de 5 micrometros. coradas pelo hemalúmen-cosina e tricrômico de gomori, examinadas e fotografadas em fotomicroscopio 7.eiss.

\section{Microscopia eletrônica de varredura}

Por amostragem, e em "duplo cego", empregou-se uma córnea de cada grupo. Concebeu-se laxê-lo nos periodos de 2.15 c 30) dias de observação. Fraçocs representativas foram corladas. lavadas em soluçio tampào de fosfato de sódio 0.1M. pll 7.6. fixadas em glularaldeido a $2 \%$ na mesma solução tampaio, por 48 horas, a $5^{\prime \prime} \mathrm{C}$. Posteriormente, foram lavadas cinco vezes na solução 


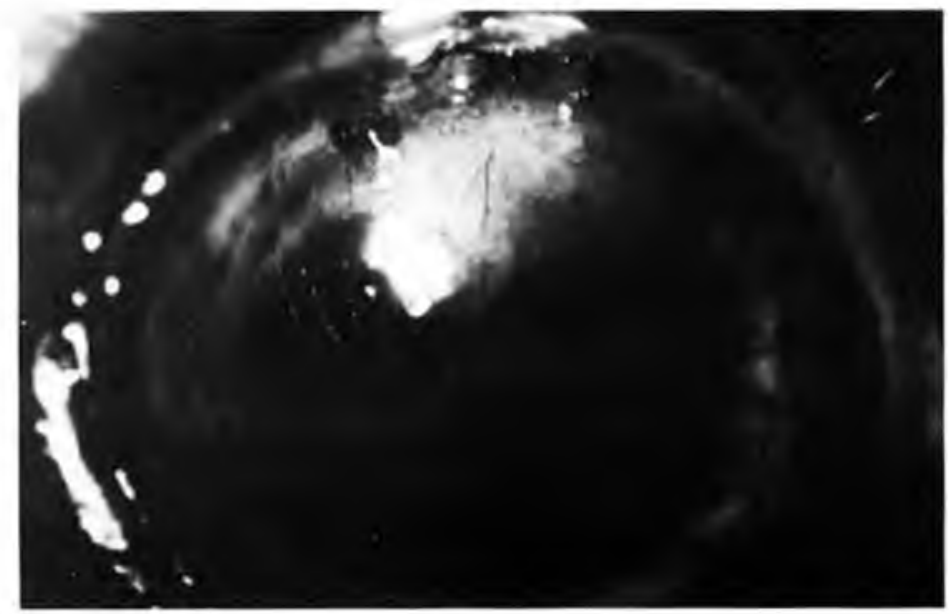

Figura 1

Imagem folográfica de ceratoplastia por enxerto autógeno de córnea, aos 60 dias de pós operatório. Nolar edema circunjacente às zonas de enxertia, neovasos superficiais e integridade do enxerto.

lampào pura, pós-fixaddas em tetroxido de ósmio a $1 \%$, no mesmo tampaìn a a mesma lemperatura. por duas horas. A seguir. foram novamente lavadas como mo caso anterior. e desidratadas em etamol, utili/ando-sc a scric: 30, 50, 70, 80, 95 e 100\%, (15 a 30) minutos em cada). () processo foi executalo a frio, repetindo-se. finalmente, duas passagens em álcool absoluto à temperaturat ambiente. A secagem foi realizada em secador de ponto critico a balse de dioxide de carbono. I:m seguida. as amostras foram montadas em "porta-objeto" apropriado, com fita adesiva de cobre. recobertas com lina camada de ouro paládio, de aproximadamente $35 \mathrm{~mm}$ de espessura. em metalizador Jl:()1. modelo Jl: ( 1100. observadats e cédron-micrografadas em microscópio eletronico de varredura mokelo JSM 25S11 (Simtos". 1092).

\section{RESULTADOS}

\section{A aliação clínica}

() cestudos mostratram, na ordem, fofofobia com marcanto variaça individual. Verificon-se tendencia à diminuiçào é desaparceimento deste sinal no decurso dos periodos de avaliação.

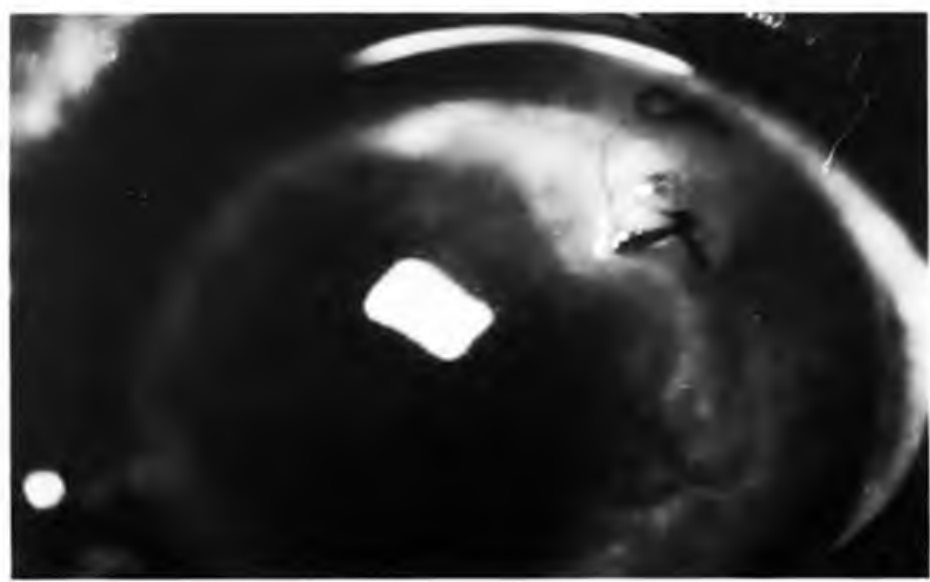

Figura 2

Imagem folográfica de ceratoplastia por enxerto autógeno de conjuntiva, aos 60 dias de pós-operatório. Notar edema circunjacente às zonas de enxertia, neovasos superficiais e integridade do enxerto.

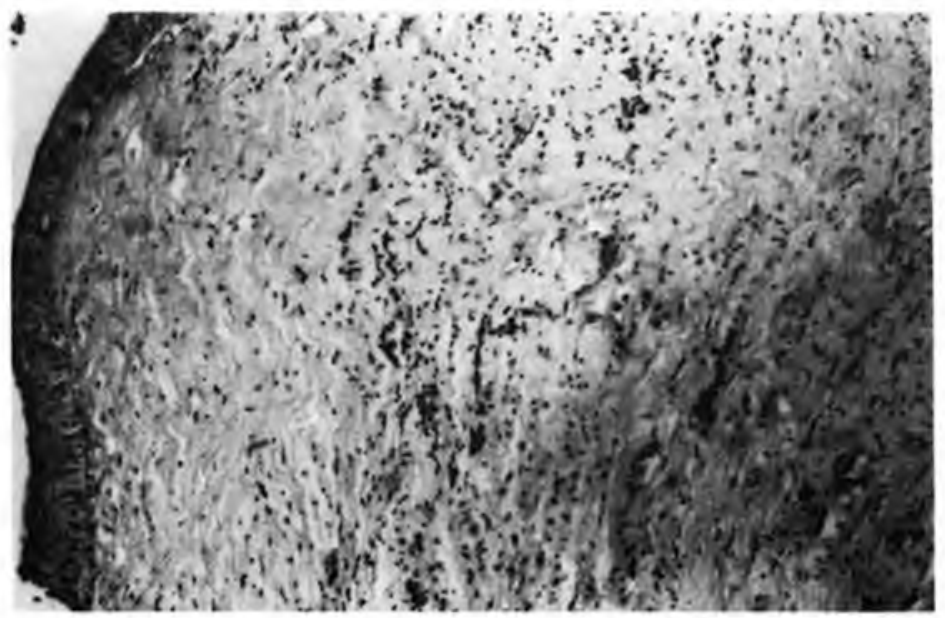

Figura 3

Folomicrografia de córnea que recebeu enxerlo aulógeno de córnea com sete dias de evolução. Notar tecido fibroso com espessamento intenso do epitélio e do estroma, neoformação e congestão vasculares, aumento do calibre dos vasos e presença de infiltrado de leucócitos polimorfonucleares e mononucleares. Coloração - Hemalúmen-eosina, Aumento - $240 \mathrm{X}$.

Cabe elucidar yae nio se observaram diferençals entre lécnicas.

Secreçes foram pesquisadas de forma quali-quantialtiva. para os tipos scroso, seromucoso, mucoso, mucopurulento e purulento. Pôde-se observar maior ocorrēncia das formas macosal e mucopurulenta, igualmente sem diforenças malrantes entre as ricuicas.

Nébula, denotando desarranjo das lïbras estromats e edema, concentrou-se nas adjacências das afreas de enxertia. Verificou-se de ausência a graus intensos nos periodos inciais. moderação nos intermediários e endência à diminuiçáo no decurso dos tempos

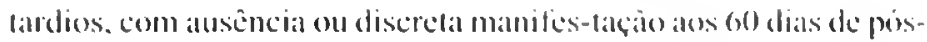
operatiorio.

Sinais referentes a ncovasculariatcà foram imvestigados segundo sua intensidade ce relaçào com os periodos pes-eperallorios.

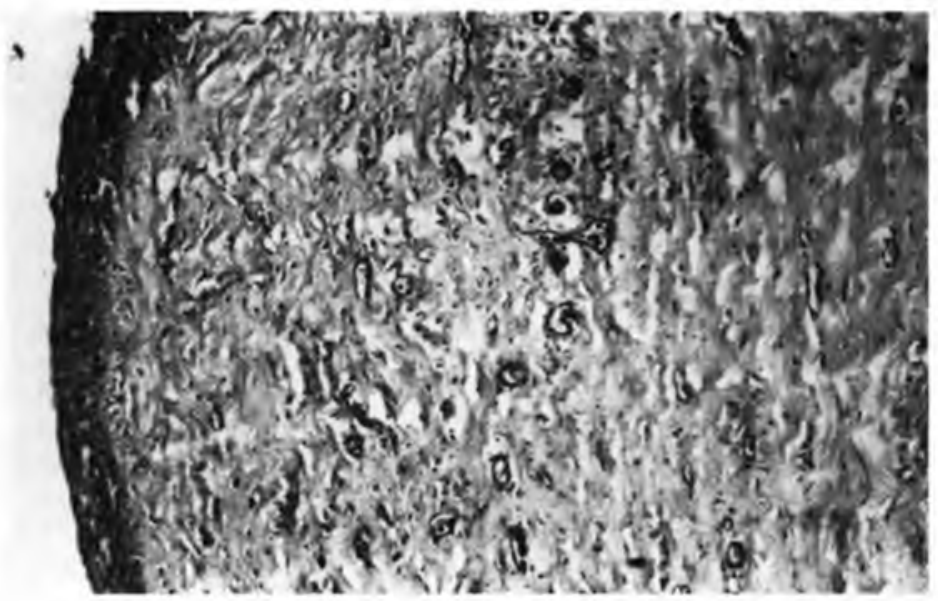

Figur. 4

Folomicrografia de córnea que recebeu enxerto aulógeno de conjuntiva com sete dias de evolução. Notar tecido fibroso com espessamento intenso do epitélio e do estroma, neoformação e congestão vasculares, aumento do calibre dos vasos e presença de infiltrado de leucócitos polimorfonucleares e mononucleares. Coloraçōo - Hemalúmen-cosina, Aumento - 240X 


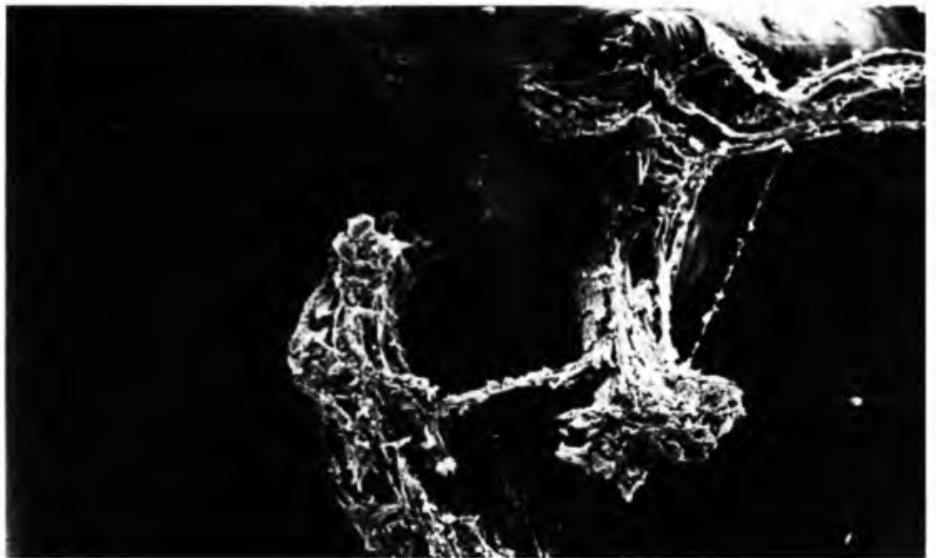

Figura 5

Imagem elétron-micrográfica de varredura em ceratoplastia por enxerto autógeno de córnea. Notar a epitelização a partir da transição entre o enxerto e a córnea (15 dias de pós-operatório), Aumento - 45X.

Assumiram maior importancia entre a segunda e a cyuarta semanals. com lendência à diminuição nas fases tardias.

Incorporacio dos enxertos ais cómeas receptorals deu-se nas duats lecoicas, porem. no tempo, mais precocemente nas enxertias de corneal em corméa.

Pode-sc observar. comparativamente aos procedimentos, que os lenomenos clinicos não divergiram (Figs. 1 e 2 ). () estudo permitiu verificar maior aderencia dos enxertos nas ceratoplastias córnca-comea. Os implantesconjuntivais mostraram-se mais frágeis e aderiam-se mais tardiamente.

\section{Avaliação morfológica}

Na avaliacion das cómeas que receberam os enxertos de cómea e nas que receberam os de conjuntiva empregou-se critério comparativo eom áreas normais. Neste sentido. definiram-se como metas de avaliagão: congestão, edema, hemorragia, neoformaça vascular. librose e infiltrado de leucócilos polimorlonucleares e monomucleares. As alteraçoes observadas e consideradas relieremse as cncontradas junto as bordas da cornea receptora e as do enxerto.

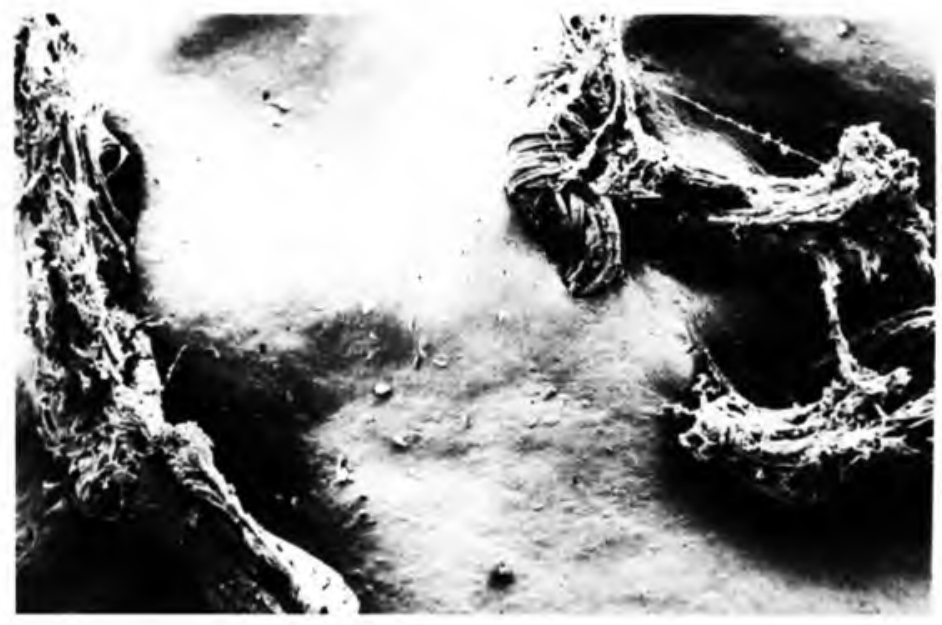

Figura 6

Imagem eléłron-micrográfica de varredura em ceratoplastia por enxerto autógeno de conjuntiva. Notar a epitelizaçāo a partir da transiçāo entre o enxerto e a córnea (15 dias de pós-operatório), Aumento - 45X.
Nas enxertias de corncia, observaram-se. com um e dois dials. intensa congestão. que se reduriu com sele dias, mantendo-se constante ate os 30 dias para. em seguida, formar-se ausente. () edema. nesta lase, apresentou-se em intensidade semelhante a descrita para a congestão. Posteriormente. com sete dias. house redução e a partir de 15 dias não mais cra observado nas bordas do enxerto. Aos sete e no decurso dos dias que se seguiram. " fenomeno nào mais foi visto. Vasos neolormados mostraram-so com intensidade discreta. Leucócitos polimorfonucleares loram mais evidentes nos periodos iniciais. A cinetica dals cilulas mononucleares foi divergente. com maior concentração alos sele e 15 dias.

Nos conertos de conjuntiva. os parametros avaliados foran os mesmos cos achados muito próximos. ('om um e dois dias após a cirurgia. a congestão foi significativa. Vasos. quando presentes. mostraram-se intensamente ectasiados e preenchidos por hemácias. nass proximidades do limbo. A avaliação da celularidade permitiu encontrar inliltrado leucocitario com predominio de polimorfonuclearese poucascelulas monomucleares. Os parámetros mantiveram sua intensidade até o décimo quinto dia de observaçào. para em seguida decrescerem gradalivamente. Leucócitos polimorfontecleares apresentaram acentuada reduçio aos sete dias. mantendo-se até os 15 dias. A partir dos 30 dias. estas células nào loram mais observadas. A cinctica dos mononucleares foi divereente. com maior concentraça aos 7 a as 15 dias. Fibrose foi vista a partir do sétimo dia. Aos 15 dias, apresentou-se à semelhança aos 7 e em menor concentração aos 30 e 60 (lias (Figss. 3 e 4 ).

A microscopia eletronica de varredura evidenciou epitelizaçào das áreas de enxertia jả ao segundo dia de implantação. Aos 15 dias. verificaram-se células pavimentosas nas areas enxertadas com limites e formas semelhantes as da cornea nomal (Figs. 5 c (b). Aos 30 dias, as árcas do enxerto mostraram-se morfologicamente iguais às da cómea integra. ()bservou-se, ainda. aspecto semelhante a "gramuloma de ponto". Por ocasião dos 30 (lias, visualizaram-se projecoesciloplasmaticas (microvilosidades.) das enxertias. semellantes as da superlicie corneana normal. (), lenomenos não divergiram signifi-calisamente cutre os procedimentos comparados:

\section{DISCUSSĀo}

A cómea lora utilizada como um dos materiais biológicos em face das suas caracteristicas. A litcratura apresental o papel da conjuntiva. quando usada na reparaçào corncana. moslrando sua capacidade em se "Iranseliferenciar" em epitélio ou formando importante base biológica de substituiçào"t.

No que concerne ao que lora delimeado e anos fenomenos que se mostraram relevantes, destacam-se. inicialmente. os quadros de fotofobia evidenciados quali-cuantilativamente e de forma análoga para ambos os métodos. Manilista-se por dor. frente á estimulaçào

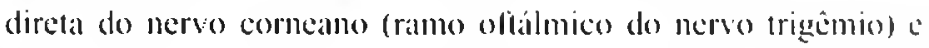
espasmo do músculo cilialr. secundario a uveitc anterior ${ }^{-2}$. No estudo. deu-se de forma mass importante no decurso das duas primciras semanas. mormente nos sete dias inicials.

Tipos e graus de secreçào, com a predominância da forma mucóide. evoluiram tendendo a exigüidade no decurso do tempon.

O edema deu-se nas adjacências das áreas de enxertia. para 


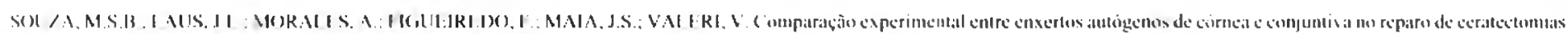

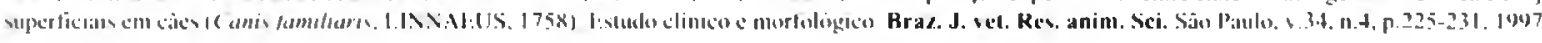

as duas leconicas estudadas, () achado c justiflcado dada as grandes perdas de areas epiteliais "s.èt. Sua apresentaçá externou-se em grau moderado nos periodos iniciais, tendendo a diminuiçio. com retorno i transparincia. no decurso do tempo. I:m apenas um animal a evoluçao deu-se de forma lenta, comparativamente ass demais cajes. I:dema em corncal for referido por Bernis ${ }^{4}(1980) \mathrm{cm}$ enxertias autógenas. Kudva: Deshpande"t (198.3) c Panchbhai: Kulkarni-20.27 (1986 \& 1987) reportaram transparencia em córncis enxertadas, decorridos 20 dias da cirurgia. Brightman ef al. ' (1989) relataram a ocorrência do fenomeno cm procedimentos anilogos, decorridas 16 semanas apos os procedimentos cirúrgicos. Em enxertias autigenas de comjuntiva. Scagliotti ${ }^{32}(1988)$ limitou-sc a citar o fenomeno a a monti-lo as citaçóes de outros $17,39,40,-42$.

Doredesconforto, associados com edema de cómear. resultam da ruptura da incraação sensorial que se mostra abundante no epitedio. (com a progressio do edema, grandes areas teciduais são destacialas da membrana basal subjacente. () edema secundairio esta associadocom grande desconforto, acompanhado por folofobia e epifora signifieantes. $A$ fotofobia é resultante da dispersão da lus. pelo celema. bem como do processo inflamatorio. A estimulaçào reflexa resulta cm epifora (. A (yuarcllal.1984).

Neolormaçán vascular deu-sc a similitude das observaçoss

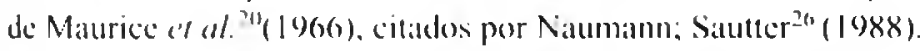
Descreveram os atulores sual corrclaçio com latores angiogênicos quimicos. somido a barreira funcional normal doestroma compacto. Rochels" (198t). citado pelos mesmos autores, mostrou que mediadores inflamatorios atuam significativamente na genesc da neoformaçán vascular. Alis am ass citomembranals da estrutura corncana. indurindo a sintese de prostaglandinas dependentes da cicloxigenasc, com conscyüente vasodilataçăo e aumento da permeabilidade vaticular. () femomeno apresconta-se com maior eridencia quando da liberaçio de histamina. Lim dos mediadores. a interleucina- 8 (II- 8 ). \& citocina multifuncional com elieito angiogenico e promotor de yumiotaxia leucocitaria. Stricter at al. (1992) mostraram que a $11-8$ o liberada da matris cormeina extracelular é age na modulaçio da reparaçào corncana. aluando no crescimento de neovasos limbicos que se dirigem ao foco da lesion.

Nas corncas que receberam as enxertias, a manifestação deu-se ao linal da primeira cinicio da segunda semanas. com vasos de contornos pouco delimitados. I louve tendencia à regressiánentre a quartal a a sextal semanas. lim tres animars. o fenomeno deu-se em intensidade comparativamente maior e com regressào mais lenta. Pode-se obsers ar. na comparacio entre as tecnicas. que nas enxertias de conjuntiva o yuadro vascular disergiu pouco significativamente. Achados condizentes para enxertias autógenas de córnea em conea foram referides por Bernis ${ }^{4}(1980)$. Mishra? (1981). Panchbhai: Kulkarni2b (1986) e Brightman ef al. (1989). Não obstante. somente Bernist $(1980)$ discorréu sobre sua evoluçào clinica. patente ao termino dos primeiros 30 dias de pós-operatório. No periodo. o fenomeno nào loi relatado em enxertos conjuntivais $16,27.32$. Scagliotti32 (1988) observou neovalicularizaçào já alos de\% dias de pós-enxertia. com perpetuaçào do quadro por atte três semanats. Kuhns ${ }^{17}(1979)$ comunicou neolormação vascular entre 24 horas c seis dias apos o ato cirurgico. () quadro nao é exclusivo as coratoplastias, ocorrendo de mancira quali-quantitativa similar em outras enfermidades da cormeal.

Relativamente a stla apresentação clinica, os vasos se dividem acompanhando ce contornando as lesòs. A manilestaciào é mais evidente e intensa nos processos cronicost. Jobim"1 (198.3) informou que os vasos progridem do limbo para imvadir a cormea em cerca de $1 \mathrm{~mm}$ ano dia.

( Elulas polimorfonucleares foram evidentes aos um e dois dias de pos-operatorio, de forma intensal nas enxertials de cornca e moderada nas de conjuntiva. Aos 1.5 dias, as mesmas incianam sua regressaio, lendendo ao desaparecimento. Nasisse ${ }^{24}(1985)$ Kern $^{12}$ (1990) reiteraram que tais élulas chegam a lesão pelo filme prélacrimal, ja as primciras horas apos o trauma. promovendo debridamento proteolitico. Säo substituidas por células mononucleares, a partir do terceiro dia, que promovem fagocitose dos restos celulares ${ }^{7.12}$. Observou-se na pesquisa aqui delincada, a manifestaçào do fenomeno a partir do primeiro e do segundo dias. e sua perpetuaçào no decurso de 15 dias, para. entao, tender a diminuição, em ambas as técnicas.

Quadros de congestano apresentaram-se similares, em intensidade, nos periodos inciais e intermediarios. Para os tardios. os achados foram signilicativos e patentes nas enxertias cormeacórnca. A condição, intrinseca à respensta in llamatória desconcadeada pela ferida cirurgica. den-se em sua forma habitual. Por sua interpretaça, ratifica-se Iratar-se de finomeno que se manifesta nas fases inciais da resposta in llamatoria, sendo a ela incrente?

Relativamente a fibrose, of fenomeno exibitl-se já alos sete dials apos a cirurgia. em gratu discreto e ou moderado para os enxertos de cómea. porim intenso nos de conjuntiva. retratando trattar-se. a conjuntiva. de tecido menos incrte a cornca receptora. Nas fascis lardias, constatou-se ausência de diferenças importantes entre als técnicas. (O) achado decorreu de librocitos, convertides a partir de coratocitos, yue na fase proliferativa secretam coligeno conferindo resistencia à firida cirurgical 72.24

fistudos, à microscopia. sobre fenomenos envolvidos com a cicatrifaçäo em enxertias de cómea foram pouco referides na literatura. No caso presente, estes mostraram padroes classicos de inflamação e reparaçào do tipo cicatricial. de mancira similat para ambals as técnicas

Poucosic encontrou sobre estudos cm microscopia cletronica de varredura. Da analise comparativa denofou-se. ji ans dois dias. recobrimento da transiçio entre a comea sadia e as areals de enxertia. () lenômeno deu-se por deslizamento de células epitcliats circunjacentes. Ambas as enxertias mostraram semelhança de superficie. quatndo observadas pela elétron-micrografia de varredura. Thoft ${ }^{+1}(1989)$ referiu-sc a capacidade do epitélio comjuntival de se "Iransdiferenciar" en córnea. Os aspectos observados bascaram-se nas formas das células e em suas projeçoes citoplasmáticas, semelhantes às da cormea intacta. Projeçoses citoplasmáticas (microvilosidades?) mostraram-sc patentes alos 15 dias. para ambas as lectnicas. Os fenomenos deram-se segundo os processos reparativos clásicos que, no periodo, apresentaram-se já consignados. Células epiteliais pavimentosals tomaram formas "identicas" as da cómea normal. para als duas técnicas estudadas. Projecooses citoplasmaticas foram analogamente citadas por Brightman e' al.$^{5}(1989)$. 


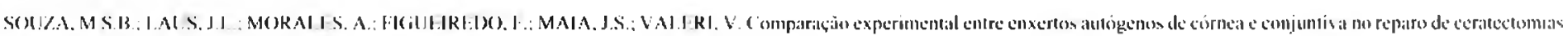

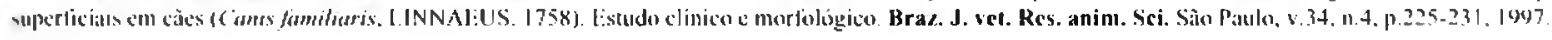

\section{CONCLUSÕES}

- As conxertias autogenas de córnca c conjuntiva cvoluiram de forma scmelhante, segundo os parámetros adotados para a analise comparativa.

- As concrtias autogenas de cornca co conjuntiva são bem toleradas e constituem-se em métodos de valor para a reparação de cóncas aviltadas por eeratotomias superficiais.

\section{ACIRADECIMENTOS}

Os autores agradecem à Fundaçion de Amparo a Pesquisa do F Sstado de São Paulo-FAPESP, pelo apoio linanceiro.

\section{SUMARY}

Lamellar keratoplasty using fresh autologous grafts of cornea and conjunctiva was studied in thirty one healthy, adult, male and female dogs. Lamellar keratectomies were accomplished removing corneal lamellar bottoms composed of epithelium and half thickness corneal stroma using a $0.5 \mathrm{~cm}$ diameter punch (trephine). Grafts were taken from the cornea and autogenous bulbar conjunctiva. They were sutured at the host cornea using an interrupted suture with a number eight ophthalmic silk thread. The graft evolution was evaluated at 1,2,7, 15, 30 and 60 days postoperatively. Transplanted corneas showed edema, neovascularization, congestion, hemorrhage, polymophonuclear and mononuclear cells infiltration, and delayed fibrosis. There was a decrease in inflammatory cell infiltrate at the latter evaluation times. By the sixtieth day, the graft areas began to show points of transparency. There were no differences between the procedures studied. The scanning electron microscopy showed epithelization of graft zones within two days of graft implantation. Fifteenth days after surgery, pavement cells were present at the host areas. By the thirtieth day, the grafted areas were morphologically similar to the normal cornea with granulomatous tissue around the suture lines. Cytoplasmatic projections similar to that of the normal cornea surface were present at grafted area. The clinical and morphological results with the two techniques employed to repair corneal injuries were similar.

UNITERMOS: cornea, surgery, transplantation, dogs, graft.

\section{REFERÊNCIAS BIBLIOGRÁFICAS}

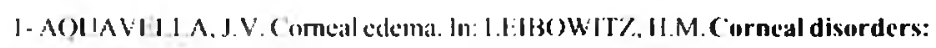
clinıal diagnosis and mannagement. Philadelphia: W. B. Saunders, 1984 p. 164$\times 2$

2- BARRAQLIR. J.I. QUCralaLtia laminar anterior. In:( URSOINJIER.NACIONAI.

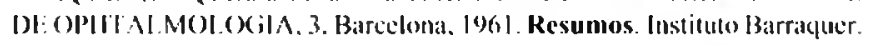
D. 382 .

3- BARROS. P.S.M.: SAFATLL: A.M.V.: MALIRBA. T.A.: BURNIL:R JR.M. Reparaläa cirurgécal da cornea de càes usiando pericárdio de eqüino conservaldo em glicerma. In:C (ONC BRI:SSO) IBRASII IIIRODA ANC I.IVI:PA. 13. (iramado. 1990). Resumos. (iramado, Anclivepa, 1990. p.11.

4- BERNIS. W. O. C Cratoplastia lamelar experimental em càcs. Arquivos da Escola de Veterinária da Universidade Federal de Minas Gerais. Belo Horizonte. ง.32. 1..3, p.305-23, 1980 .

5- IBRIGIITMAN, A.H.: MCLAUGHHLIN. S.A.: BROGiDON, J.D. Autogenous lamellar comcal gralling in dogs. Journal of the American Veterinary Medical Association, Schaumburg, v. 195, n.4, p.469-75, 1989.

6- BRRIK, 1). Aplicação de pelicula de celulose em lesōes epiteliais da cómea. Fstudo experimental comparativo. Revista Brasileira de Oftalmologia, Riode Janeiro. V.50, n.4. p.23-8, 1991 .

7-COTRAN.R.S.: KUMAR. V.: ROBBBINS. S.I. Patologia esIrutural efuncional 4.cel. Rio de Janciro. Ciuamabara Koogan. 199. p.3.3-72.

X. CIARCIA. J.A.: BARROS. IPS.M.: LAUS, J.L.: PI:RI:IRA, A.L. Implante de peritonio homologo conservado apos cerateclomia lamelar em ciales. In: (ONCIRI:SSO BRASILIIRO DA AN(LIVIBPA. 15.. Rio de Jineiro. 1993. Resumos. Rio de Janciro. Anclivepa, 1993. p. 74.

9- (iIRARI). I. J Corneal surgery. Si L.ouis, Mosby 1981. v.2. p.2-2.38: Advanced kechniques in ophthalunic microsurgery
10- CiUMAR X̀I:S. R.Q. Ceratoplastia interlamelar xenógena de galinha em

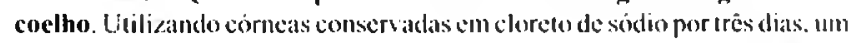
més c 14 anos. Isstudo biomicroscópico e hisopalológico. Belo Horizonle. 1979. Tesc (1)outoriddo em oftalmologial) - Liniversidade Federal de Minas (ictriis.

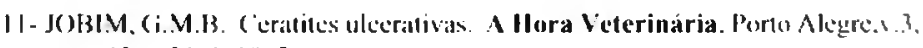
n. 13, p.31-4, 1983.

12- KI:R.N, T.I. Lilcerative kerattlis. Veterinary ( linies of North America. Small

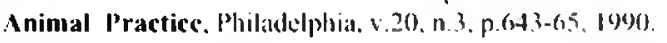

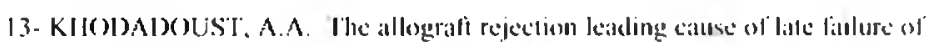
clinical corneal gralts. In CORNEAL, GRAFT FAII.URE CIBA FOUIN-

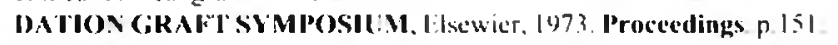

14-KHODADOUST. A.A..SII.VI:RSTKIN. A.M. Transplantation and rejecion ol individual cell layers of the cornca. Investigative Ophthalmology. St. I.ouis. v.8. p.180-95. 1969.

15- KOLNING. S.13.. KAUIMAN. 11.1:. The Ireatment of necrentiring seleriting an aulogenous periosical graft. Ophthalmic Surgery. Thorettate. v. 14. p. 1(1)29-32. 1983.

16- KUDV^. V.. DESHPANDI:, K.S. Experumential auldegenous and homogenous lamellitr comcal gralting in bovines. Indian Veterinary Journal. Madras. v.60, n.1. p.56-61. 1983.

17- KUHNS, F.. .. Conjuctival palch gralis for treatment of concal lesions in dengs. Modern Veterinary Practice. v.60. n.4. p.301-5. 19799.

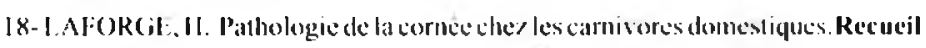
de Médécine Véterinaire E. Alfort., Cedex, v. 165, n. 3, p.247-56, 1984)

19-1.AUS.J.I.:ROSSI. M.A.: BARROS.P.S.M.: SOU\%A. M.S.B.: MORA.ES.A.

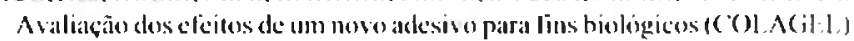

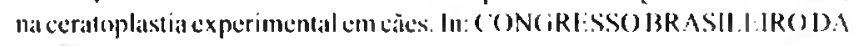
ANCIIVI:PA. 15. Riode Janciro. 19)3. Resumos. Riode lanciro: Anclivepa. 1993 . p. 72.

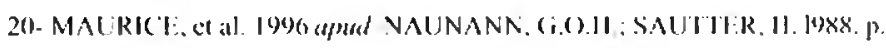




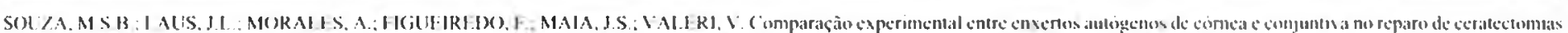

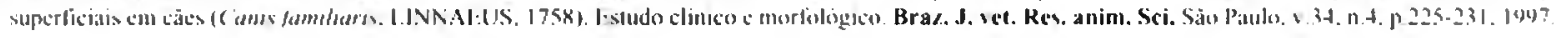

21- MHI)IIROS. O.T. Fistudo biomicroscópico c imunológico da ceratoplastia experimental em coclhos, com córneas autólogas c homologas frescas conservadas em câmbara ủmida. Belo Horizonte, 1973. Fese (1)outorado). IStop. Liniversidade Federal de Minas ( icrais.

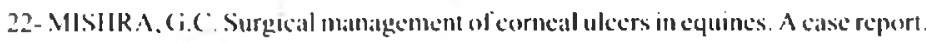
Indian Veterinary Journal, Madras, v. (18. 10. 10. 1.969-70. 1981

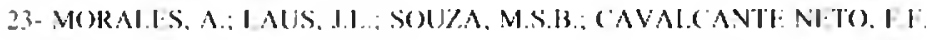

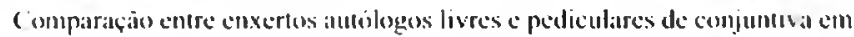

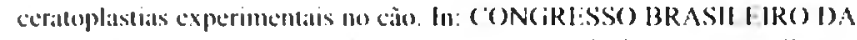
ANCLIVI:PA. 15. Rode Janciro. 1993. Resumos. Riode Janciro: Anclivepa. $199 . \mathrm{p} .71$.

24- NASISSL: M.P. (anine ulceraltive keratitis. Compendium on Continuing Fducation for the Practicing Veterinarian, v.7, n.9, p.686-98. 1985.

25- NAIIMANN, (j.0.H. SAUTTLR. II. Surgical procedures on the cormea. In BL (OD). F. C. MACKI RSEN, G., NIWBANIR. HI. Surgical ophthalmology. Berlin: Sprmger. I9Bx. v. 1, p.434-43.

26- PA.V(HBIIAI. Y S. KLI.KARNI. P.E. lamellar corneal transplantation in buflato caldes (Buhahes huhalis) - I (Autogenous and Homegenous (irafis) Indian Veterinary dournal. Madras.v.63.3. n.9. p. 737-40. 1986.

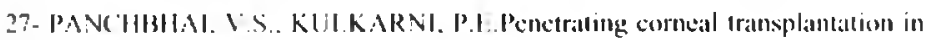
Buflialos calbes - III (Autogenous, Homogenous and l leterogenous ( irattis) Indian Veterinary Journal. Maldras, 4.64, n.3. p.223-26. 1987.

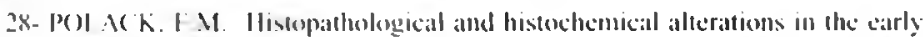
siages of cormeal gralt rejection. Journal of fixperimental Medicine, New Fork. $3.116,0.7(6)-17.1062$.

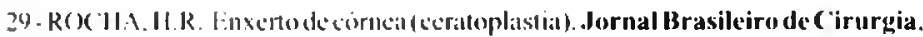
1.1. p. $446-59,1962$

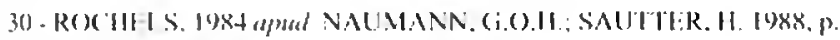

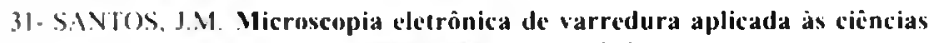

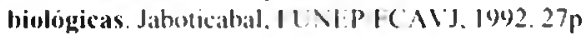

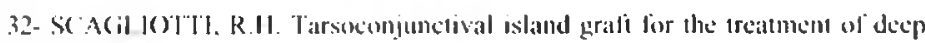
corncial ulcers. descemelececles. and perforations in 35 dogs and 6 calts. Seminars in Velerinary Vledicine and Surgery (Small Animal). s.3. n. I. (1.60).76. 1988 .

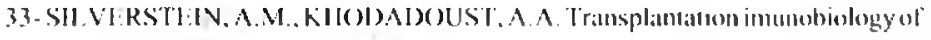
the cornea Excerpta Wedica, North Holliand, p. 105. 1973.

34- St ATTIER. D. Fundamentals of veterinary ophthalmologs 2.ed. Phuliuldelphat. W. B. Satunders. 1900) $606 \mathrm{xp}$.

35- SPOOR, T.C. a al. A periosical-1emporalis fascra pedicte flap for repanting impending ocutar perlenations and extrudeng keralloprostheses. American Journal Ophehalmology, ('hicateo. 3. 1018. 10.6. p.70)-8. 1989.

36. STARTLP. F.G. Cornecil ulceration in the dog. Journal of Simall Animal Practice. Iondon. 6.25, 11.12, p. 737-52, 1984.

37- STRILTIER, R.M. al al Interleukin-8. A corncal factor that induces neovascularization. American Journal of Pathology, r.141, n.6. p. 127984. 1902

38- THOHT, R.A.. Conjuncribal transplantatkon. Archives of Ophthalmology: ('hicago, v.95. p. 1425-27, 1977.

39- TH(OFT. R.A. Indications for conjunctival tramsplantation. Ophothalmology. Hagersiomn. 1.89. 11.4, p.3.35.4. 1982

40. THIOI-T, R.A. The role of the limbus un acular surlace mantenance and repanr.

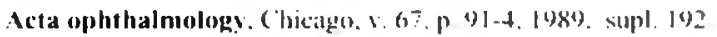

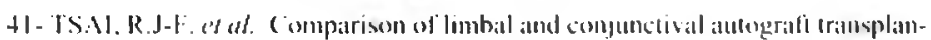
tation in corneal surfiec reconstructum in rabbits Ophthalmology. Hingersitown. v.97. 1.4. p.440-55. 1990.

Recebido para publicação: $17 / 06 / 96$ Aprovado para publicação: 17/02/97 